\title{
STUDIES ON THE BLOCKADE OF PROGESTERONE SECRETION BY GRAFTED CORPORA LUTEA IN THE PREGNANT RAT
}

\author{
GEULA GIBORI AND P. F. KRAICER \\ Department of Zoology, The George S. Wise Center for Life Sciences, \\ Tel Aviv University, Tel Aviv, Israel
}

(Received 19th Fune 1973)

Corpora lutea (GL) of pregnancy have been isolated from the other ovarian tissues as autografts under the renal capsule in rats. These grafts were maintained for a period corresponding to a full gestation provided that exogenous progesterone was available until placental luteotrophin was secreted (Gibori \& Kraicer, 1972). Despite their excellent histological appearance, however, these grafts secreted little progesterone (G. Gibori, Y. Shaham and P. F. Kraicer, unpublished observations).

This paper describes attempts to increase the amount of progesterone secreted by the CL by increasing the amount of luteal tissue grafted and by supplying supplemental substrate.

In our technique, only the bulging domes of the CL were used and it seemed possible that the total mass of grafted CL may not have sufficed to produce adequate amounts of progesterone (Kraicer, 1969). As a test of this hypothesis, five rats were given their own CL plus the CL of five other pregnant donors as grafts on Day 4 of gestation (Day $0=$ vaginal spermatozoa). Thus, each rat bore approximately fifty auto- and homotransplanted CL. Exogenous progesterone was supplied, as solid implants, until Day 13. At autopsy on Day 21, all grafts were found to be in excellent condition but there was no improvement in the maintenance of gestation. There were no living embryos and the total number of placentae $(4 \cdot 0 \pm 0.2$ was not greater than in animals with only eight to ten autografted CL $(\vec{P}=0.19$ by Student's $t$ test).

Since the limiting factor did not appear to be the quantity of luteal tissue present, the possibility that the steroidogenic activity of CL tissue was adversely affected by isolation and grafting was considered. Three alterations in steroid metabolism could be responsible: (1) decreased conversion of cholesterol to pregnenolone ( $3 \beta$-hydroxy-5-pregnene-20-one) and progesterone; $(2)$ increased utilization of progesterone for synthesis of androgens and oestrogens; and (3) increased activity of $20 \alpha$-hydroxysteroid dehydrogenase leading to conversion of the progesterone to its inactive catabolite, 20 -hydroxy-4-pregnene-3-one. The latter two pathways do not appear to be responsible for the low amount of progesterone secreted (Gibori \& Kraicer, 1973; G. Gibori, P. F. Kraicer, S. A. Lamprecht and H. R. Lindner, unpublished observations). In this study, we tested the possibility that the first mechanism is operative. 
Rat CL grafts were excised and quickly frozen on Day 13 of pregnancy. They were sectioned in a cryostat and incubated for demonstration of $3 \beta$-hydroxysteroid dehydrogenase activity with both pregnenolone and dehydroepiandrosterone as substrates, with equally satisfactory results. The intensity of diformazan deposition from Nitro Tetrazolium Blue indicator was as great as that in the CL from the ovaries of normally pregnant rats. There was no indication that conversion of pregnenolone to progesterone was in any way rate-limiting.

Having shown that pregnenolone could be converted to progesterone in vitro, we tested the ability of the CL grafts to secrete enhanced amounts of progesterone when supplied with exogenous pregnenolone in vivo. Implantable pellets of pregnenolone were prepared by suspending $50 \%$ of powdered steroid in Silastic 382 Medical Elastomer (Kraicer, 1972). (This is the highest concentration of steroid which can be used. At higher concentrations, the implants cannot be fabricated.)

An attempt was made to supply pregnenolone directly to the grafted CL by placing two implants, $2 \mathrm{~mm}$ diameter $\times 0.2 \mathrm{~mm}$ thickness, under the renal capsule next to the grafts. This is the largest implant which can be inserted under the renal capsule. By weighing the implants before and after insertion, it was calculated that they lost, on average, $32 \mu \mathrm{g} /$ day in weight. This was assumed to be a measure of the rate of release of steroid. Twelve pregnant rats with CL grafts were given these implants on Day 4 at the time of grafting. Exogenous progesterone was given as subcutaneous implants (Kraicer, 1972) between Days 4 and 13. There was no improvement in the maintenance of gestation. All animals had surviving placentae in utero, but no fetuses survived to term.

The rate of supply of pregnenolone by these local implants was too low to allow definite conclusions to be drawn. At the time of peak secretion of progesterone in the pregnant rat, each ovary secretes approximately $300 \mu \mathrm{g}$ progesterone daily (Uchida \& co-authors, 1970). No practical method has been devised to ensure direct supply of sufficient pregnenolone to the grafted CL.

Ten pregnant rats were each given five subcutaneous implants of $50 \%$ pregnenolone at the time of grafting, on Day 4; each implant was $10 \mathrm{~mm}$ in diameter $\times 1.7 \mathrm{~mm}$ thick. On the basis of weight loss, the total daily release of pregnenolone was calculated to be between 5 and $6 \mathrm{mg} / \mathrm{rat}$. Exogenous progesterone was supplied, by two implants of the same size containing $35 \%$ steroid, between Days 4 and 13, to ensure placentation. At autopsy, on Day $21,3.8 \pm 0.7$ (mean \pm S.E.) placentae were found in their uteri. No living fetuses were found. In a control group of ten rats given pregnenolone implants until Day 13 only, $3 \cdot 9 \pm 0 \cdot 4$ placentae were found in utero. Hence, supplemental pregnenolone did not improve the maintenance of gestation.

The enzyme responsible for the conversion of pregnenolone to progesterone, $3 \beta$-hydroxysteroid dehydrogenase, is present in the grafts. Nevertheless, this enzyme activity was not expressed in vivo as the ability to utilize exogenous pregnenolone. It appears that the biosynthesis of progesterone is deficient in grafted CL. Other steroidogenic pathways also show decreased activity, e.g. $20 \alpha$-hydroxysteroid dehydrogenase induced by ergocornine (G. Gibori, P. F. Kraicer, S. A. Lamprecht \& H. R. Lindner, unpublished). It may be that the general metabolic activity of grafted CL is limited by its vascular supply. Luteal 
tissue of the rabbit has been shown to have an exceedingly high rate of blood flow (Abdul-Karim \& Bruce, 1973). Despite the excellent vascularization of the grafted CL by the renal capsular vessels, it is probable that the blood flow through the grafted CL is considerably less than that in ovarian CL.

\section{REFERENCES}

Abdul-Karim, R. W. \& Bruce, N. (1973) Blood flow to the ovary and corpus luteum at different stages of gestation in the rabbit. Fert. Steril. 24, 44.

Grbori, G. \& KRAICER, P. F. (1972) Histological and functional analysis of the autotransplanted corpus luteum of pregnancy in the rat. F. Reprod. Fert. 31, 179.

Gibori, G., Kraicer, P. F., LAMPRecht, S. A. \& Lindner, H. R. (1973) Induction of luteolysis in luteal autografts on the pregnant rat: interactions between ergocornine and progesterone. Submitted for publication.

Kratcer, P. F. (1969) Studies on the mechanism of nidation. XXXV. Effect of removal of corpora lutea on ovo-implantation and pregnancy in the rat. $\mathcal{F}$. Reprod. Fert. 18, 175.

KRAICER, P. F. (1972) Maintenance of gestation by depot progestins in the rat. Steroidologia, 2, 257.

Uchida, K., Kadowaki, M., Nomura, Y., Mryata, K. \& Mikaye, T. (1970) Relationship between ovarian progestin secretion and corpora lutea function in pregnant rats. Endocr. jap. 17, 6. 